\title{
BEYOND THE SORPTIVITY:
}

\section{DEFINITION, MEASUREMENT, AND PROPERTIES}

OF THE SECONDARY SORPTIVITY

\section{Revision 1}

\begin{abstract}
Christopher Hall, D.Sc. ${ }^{1}$ and Andrea Hamilton, Ph.D. ${ }^{2}$
${ }^{1}$ Professor Emeritus, School of Engineering, University of Edinburgh, The King's Buildings, Edinburgh EH9 3FB, U.K. Email: christopher.hall@ed.ac.uk

${ }^{2}$ Senior Lecturer, Department of Civil and Environmental Engineering, University of Strathclyde, James Weir Building-Level 5, 75 Montrose Street, Glasgow G1 1XJ, U.K.
\end{abstract}

\begin{abstract}
Capillary imbibition in brick, stone and concrete occurs in two stages. The primary process, which occurs in the standard test to measure sorptivity, is a spontaneous imbibition in which air is displaced by the invading liquid (usally water). In primary imbibition, the displacement of air is incomplete, and some air is trapped. The residual air content lies usually in the range $0.1-0.4$ of the volume-fraction porosity. Primary imbibition is followed by a much slower secondary process in which trapped air in the interior of the material dissolves in the liquid phase and diffuses to the unsealed external surfaces where it escapes. As air is lost, there is further imbibition of liquid to replace it. Eventually, all trapped air is lost, and the material reaches saturation. There is current interest in using the rate of secondary imbibition to define a secondary sorptivity, and speculation that this may be a useful property for characterizing porous construction materials, particularly in relation to durability. This paper analyses the secondary imbibition process, and provides a definition of the secondary sorptivity which is independent of the dimensions of the test specimen. The analysis is supported by experimental data on Ancaster and Portland limestone test materials.
\end{abstract}




\section{INTRODUCTION: BEYOND THE SORPTIVITY}

The sorptivity is a well-defined transport property of brick, stone, and concrete materials, with numerous technical applications (Hall 1989). It is easily measured in simple water-imbibition tests in which the imbibition weight gain $\Delta w$ generally increases as the square root of the elapsed time $t$. The sorptivity is obtained as the slope of a $(\Delta V / A)-t^{1 / 2}$ plot, where $\Delta V=\Delta w / \rho_{\mathrm{w}}$ is the imbibed volume of water of density $\rho_{\mathrm{w}}$, and $A$ is the area of the inflow face. It is well known (Hall and Hoff 2012) that after the primary imbibition is complete, and provided that the specimen remains in contact with a supply of water, there is a further small and slow increase in weight. This is the result of the progressive escape of the air that is trapped within the material during the primary imbibition. The air dissolves and diffuses through the water-filled pores to the external surfaces of the specimen. As this occurs, further water is absorbed, and enters the pores to replace the air. Eventually (typically after many weeks or months, depending on the material and the specimen size), the entire open porosity becomes water-filled and the specimen reaches complete saturation (Gummerson et al. 1980).

There is now increasing interest in this secondary absorption (or imbibition) phenomenon (Kurtis et al. 2016; Liu and Hansen 2016), and in using a secondary sorptivity derived from it as a material property for characterization purposes (Henkensiefken et al. 2009; Li et al. 2012; Ghasemzadeh and Pour-Ghaz 2015; Wei et al. 2017). While the primary sorptivity is rigorously defined and has a clear theoretical basis (Hall and Hoff 2012), the secondary sorptivity does not. The aim of this paper is to put the secondary sorptivity on a firmer footing. The water transport processes underlying the secondary absorption are discussed, together with matters of definition, terminology, and measurement.

\section{History}

Air entrapment appears to be a general, perhaps universal, feature of the capillary imbibition of water and other liquids in porous materials (Alava et al. 2004). Liquid imbibition in dry porous materials is a process of immiscible displacement of a non-wetting phase (air) by a wetting phase (usually water). A non-zero residual content of non-wetting phase is expected from standard theory 
of multiphase flow in porous materials (Blunt 2017). Water absorption is rarely considered from this viewpoint in the field of civil engineering materials, although entrapment of air in capillary wetting has long been recognized through the concept of the capillary moisture content (Roels et al. 2004). This quantity, usually denoted $w_{\text {cap }}$, is defined in mongrel units as the weight of water in unit volume of material at the end of the primary imbibition. It is better re-expressed as the ratio of the volume-fraction imbibition water content to the volume-fraction open porosity $f$, that is $\theta_{r \text {,cap }}=w_{\text {cap }} /\left(\rho_{\mathrm{w}} f\right)$, where $\rho_{\mathrm{w}}$ is the water density. Defined in this way, $1-\theta_{r \text {,cap }}$ is the fractional residual air content. For a variety of brick, stone and cementitious materials, $\theta_{r \text {,cap }}$ lies mostly in the range $0.6-0.9$, so that the fraction of the porosity that is occupied by trapped air, $\lambda=1-\theta_{r, \text { cap }}$, is correspondingly in the range $0.1-0.4$. It was recognized, certainly by Hens (Hens 1976) and perhaps earlier, that after primary imbibition is complete water continues to be slowly absorbed, and that led to the "two-tangent" method of determining $w_{\text {cap }}$. However, no significance was attached to the rate of the secondary imbibition. The capillary moisture content (or the closely related saturation coefficient) has been used over many years as a guide to durability, especially in relation to freeze-thaw damage in building stone (Hirschwald 1912; Schaffer 1932). However it has not been shown that $w_{\text {cap }}$ is a true material property, independent of the dimensions of the test specimen. Nor has much effort been spent on its theoretical interpretation. Long-term water absorption and associated air-diffusion have also been studied in relation to freeze-thaw damage in air-entrained concretes (Fagerlund 1993).

Around 2004, ASTM C1585 (ASTM 2004), a standard mainly concerned with the primary sorptivity of concretes, first described a longer-term test in which the imbibition is extended well beyond the primary stage, typically for up to 7 days. This standard defined for the first time a "secondary rate of water absorption", obtained from the slope of the second-stage $\Delta w-t^{1 / 2}$ plot. This quantity is defined by the equation

$$
i=S_{\mathrm{s}} t^{1 / 2}+\text { const, }
$$


where $i=\Delta w /\left(\rho_{\mathrm{w}} A\right)$, and $A$ is the area of the immersed face. Here $t$ is the time from the beginning of the test. Like the sorptivity $S$, the quantity $S_{\mathrm{s}}$ has dimension $\left[\mathrm{L} \mathrm{T}^{-1 / 2}\right]$, and the same units, commonly $\mathrm{mm} / \mathrm{min}^{1 / 2}$. In technical publications (Henkensiefken et al. 2009), $S_{\mathrm{s}}$ is now often called the secondary sorptivity.

\section{AIR DIFFUSION IN SECONDARY ABSORPTION}

Fig. 1 shows an example of long-term spontaneous imbibition in a small block of limestone material. Distinct primary and secondary stages are apparent. Here the primary process is complete in a few hours, but the secondary process takes several months to reach a final state in which the material is fully saturated.

Primary imbibition occurs by absorption of water through the inflow face under the action of capillary forces (Fig. 2a). Provided that the test specimen has constant cross-sectional area $A$, and is dry and homogeneous, the quantity $\Delta V / A$ increases as $t^{1 / 2}$, the square root of the elapsed time, until the leading edge of the wet front approaches the end of the specimen. The rate of imbibition then falls rapidly, and the primary process is complete. The volume-fraction water content $\theta$ of the specimen is now uniform. During primary imbibition, $\Delta V$ is proportional to $A$, and does not depend on the other specimen dimensions, although of course the specimen length $L$ limits its duration. In most porous construction materials (brick, stone, and concrete), the capillary forces acting on the water are much stronger than the gravity forces, whose influence can usually be neglected.

At the end of the primary process, the wetted specimen and its trapped air are at mechanical equilibrium, with the water at constant capillary pressure throughout. However, the system is not at mass-transfer equilibrium because the pressure of the trapped air is higher than that of the atmospheric air at the surfaces of the specimen. Since, by Henry's law, the solubility of air in water is proportional to its pressure, the concentration of dissolved air in the interior of the specimen is greater than that at the surfaces. This concentration difference sets up a diffusive flow of dissolved air to the specimen surfaces (Fig. 2b). The volume of trapped air slowly decreases. The air is replaced by water drawn in by capillary forces. These coupled processes are the cause of the secondary imbibition. Since the solubility of air in water is low, and molecular diffusion a slow 
process, the timescale of secondary imbibition for typical sizes of test specimens is measured in months, often many months. Even so, given sufficient time, the trapped air diffuses to the surface and observations show that test specimens eventually reach a state of saturation in which the entire open porosity is filled with water (Gummerson et al. 1980). It should be noted that secondary imbibition is controlled by air diffusion to all unsealed faces of the test specimen, since all such faces (including the inflow face) are at equilibrium with air at atmospheric pressure. This is in marked contrast to the primary process in which water enters the specimen only at the inflow face.

A sharp-front model of the air-diffusion process (Hall and Hoff 2002) provides a description of the secondary process. It is assumed for simplicity, and in the absence of other information, that the pressure of the trapped air remains constant as its volume decreases. Since the rate of air diffusion decreases as the distance from the surface increases, a zone of saturation, thickness $x_{\mathrm{sf}}$, moves inwards from each face (Fig. 2b).

The total volume of the saturation zone $V_{\mathrm{sz}}$ depends on the geometry of the test specimen. For a rectangular block $a \times b \times c,(c \leq b \leq a)$,

$$
V_{\mathrm{sz}}=F x_{\mathrm{sf}}-E x_{\mathrm{sf}}^{2}+8 x_{\mathrm{sf}}^{3}
$$

where $F=2(a b+b c+c a)$ is the total face area of the block, and $E=4(a+b+c)$ is its total edge length. The volume of water in the saturation zone due to secondary imbibition $\Delta V_{2}=\lambda f V_{\mathrm{sz}}$, with $\lambda$ and $f$ as defined earlier. As is clear from Fig $2 \mathrm{~b}$, the specimen is fully saturated when the saturation zone extends inwards a distance of one-half of the shortest edge length. That is to say, the volume of the saturation zone reaches a maximum value, $\max \left(V_{\mathrm{sz}}\right)=a b c=V_{\mathrm{tot}}$, when $x_{\mathrm{sf}}=c / 2$. This maximum value marks the end of the secondary process, where $\max \left(\Delta V_{2}\right)=\lambda f V_{\text {tot }}$, and the total imbibed water $\max (\Delta V)=\max \left(\Delta V_{1}\right)+\max \left(\Delta V_{2}\right)=f V_{\text {tot }}$, so defining a state of saturation in which water occupies all the open porosity. When saturation is reached, total volume of imbibed water $V_{\text {sat }}=f V_{\text {tot }}$.

The rate of movement of the saturation front depends on the excess pressure of the trapped air 
$\Delta p=p_{\mathrm{a}}-p_{0}$, where $p_{\mathrm{a}}$ is the trapped air pressure, $p_{0}$ the ambient air pressure at the surface of the specimen, and the diffusivity of air in the saturation zone, $D_{\mathrm{a}}^{\prime}$. There are constant-pressure boundary conditions at the surface and at the moving saturation front, so that (Hall and Hoff 2012; Hall et al. 2017)

$$
\frac{\mathrm{d} x_{\mathrm{sf}}}{\mathrm{d} t}=\frac{B^{\prime}}{x_{\mathrm{sf}}}
$$

and

$$
x_{\mathrm{sf}}=B\left(t-t_{2}\right)^{1 / 2}=B t^{\prime 1 / 2} \text {. }
$$

Here $t=t_{2}$ is the clock time at which secondary imbibition starts $\left(t^{\prime}=0\right)$, and

$$
B=\left(2 B^{\prime}\right)^{1 / 2}=\left[\frac{2 D_{\mathrm{a}}^{\prime} k_{\mathrm{H}} \Delta p \mathbf{R} T}{p_{\mathrm{a}} \lambda f}\right]^{1 / 2}
$$

with the effective diffusivity of dissolved air in water $D_{\mathrm{a}}^{\prime}=D_{\mathrm{a}} f / \tau . D_{\mathrm{a}}$ is the diffusivity of air in water and $\tau$ the tortuosity of the pore system. For the derivation of Eqn 5, see (Hall and Hoff 2012).

Combining Eqns 2 and 4 gives the overall equation for secondary imbibition

$$
\Delta V_{2}=\lambda f V_{\mathrm{sz}}=\lambda f\left(F B t^{\prime 1 / 2}-E B^{2} t^{\prime}+8 B^{3} t^{\prime 3 / 2}\right) .
$$

The first term in Eqn 6 dominates for small $t^{\prime}$, so that in the early stages of secondary imbibition

$$
\Delta V_{2} / F \approx \lambda f B t^{\prime 1 / 2}
$$

and (time) $)^{1 / 2}$ behaviour is expected.

Eqn 6 also shows that $\Delta V_{2} \approx \lambda f F B t^{1 / 2}$ is proportional to the total face area $F$, not to the inflow face area $A$. The time at which the secondary imbibition is complete, $t_{\text {sat }}$, depends on the smallest of the block dimensions, $c$, and is given by $t_{\text {sat }}=(c / 2 B)^{2}$. In a cylindrical test specimen, the air diffusion to the lateral (cylinder) surface is radial outwards, and this case is described in the Appendix. 
The geometrical complications reflected in Eqn 6 for a rectangular prism, and in Eqns A1, A2 for a cylinder, can in principle be circumvented or reduced by sealing some of the faces of the test specimen. For example, in a rectangular specimen with the lateral surfaces hermetically sealed, air diffuses only to the two end faces, so flow is one-dimensional. Consequently, the second and third terms in Eqn 6 are zero, $F=2 A$, and in this case $S_{2}=S_{\mathrm{s}} / 2$. The same is true for a cylindrical specimen in which the lateral surface is sealed. Achieving this result depends of course on effective sealing, but it is not yet known if the coatings used to prevent liquid-water absorption or short-term evaporation also block slow air-diffusion.

\section{Comment on time variables}

In primary imbibition, the clock is started at $t=0$, the moment of first contact of the dry test specimen with water, and the elapsed time $t$ is therefore well defined. In writing Eqn 4, it is assumed that the time $t=t_{2}$ at which secondary imbibition starts is also well defined. Because the rate of secondary imbibition is usually $10^{2}-10^{3}$ times slower than that of the primary process, it may be acceptable to judge that the primary and secondary processes are effectively sequential, and that the time $t=t_{2}$ is defined by the end of the primary process (for example, as calculated by the two-tangent construction). This cannot be strictly correct, since air starts to diffuse from the wetted region as soon as the primary imbibition starts. However, it may be a useful approximation. It may also be acceptable for some purposes to set $t_{2} \approx 0$ and $t=t^{\prime}$ given the long duration and slow rate of the secondary process. Here, in what follows, the distinction between $t$ and $t^{\prime}$ is generally maintained.

\section{TERMINOLOGY AND DEFINITION OF THE SECONDARY SORPTIVITY}

Although the water-transport mechanisms at work in primary and secondary imbibition are different, both depend on capillarity to fill open porosity. There is therefore no objection to using the term sorptivity to describe both. The (primary) sorptivity has been defined previously as "the material property which characterizes the tendency of a porous material to absorb and transmit water by capillarity" (Hall 1989). In primary imbibition, the capillary forces act to draw water (or other liquid) into the material at a rate which is controlled by the strength of these forces and by 
the resistance of the material to the viscous flow of the water. It is assumed (implicitly) that no resistance arises from the viscous flow of the displaced air. This conforms to the accepted definition of spontaneous imbibition (Alava et al. 2004).

By contrast, the rate of secondary imbibition is controlled by the resistance of the saturated material to the molecular diffusion of air in water. This depends on the properties of air and water, and on certain properties of the material. However, the material properties involved are not the same as those controlling primary imbibition. The secondary sorptivity is determined by the rate of change of the trapped-air volume. This is a particular case of forced imbibition, in which the saturation front is close to mechanical equilibrium at all times. The strength of the capillary forces and the viscous impedance do not directly influence the rate of secondary imbibition.. As the rate of primary imbibition is generally much greater than that of secondary imbibition, the two processes may usually be treated as though they are sequential. The secondary sorptivity therefore characterizes the tendency of a porous material to release trapped or entrained air by molecular diffusion. So defined, the secondary sorptivity excludes any contribution to the release of air by advection in pore water.

A further distinction between primary and secondary sorptivity lies in the relation of imbibed volumes $\Delta V_{1}$ and $\Delta V_{2}$ to the size and shape of the test specimen (see Fig 3). As already noted, $\Delta V_{1}$ is invariably scaled by the area of the inflow face $A$ to yield a sorptivity $S$ that does not depend on the specimen shape or size. However in secondary imbibition $\Delta V_{2}$ depends not on $A$ but on $F$, the total of area of all surfaces at which air can escape. This total area includes all unsealed faces, whether immersed or not, and it may include also faces which are sealed against the rapid evaporation of water but through which air may diffuse over long periods of time. The correct experimental quantity for calculating the primary sorptivity is therefore $\Delta V_{1} / A$, while that for the secondary sorptivity is $\Delta V_{2} / F$. It is then logical to define a true secondary sorptivity by the equation

$$
i_{2}=S_{2} t^{1 / 2}+\text { const }
$$


where $i_{2}=\Delta V_{2} / F$, using early-time secondary imbibition data acceptably linear in $t^{\prime 1 / 2}$. So defined, $S_{2}$ is independent of the size and shape of the test block. It follows that $S_{\mathrm{s}}=S_{2} F / A$. As already discussed, it may be acceptable to set $t^{\prime}=t$. It also follows from Eqn 7 that in the sharp-front model the secondary sorptivity $S_{2}=\lambda f B$.

The differences between scaling imbibition data $\Delta V$ by inflow area $A$ and by total unsealed face area $F$ are shown schematically in Fig 3. To obtain a secondary sorptivity $S_{2}$ (as defined here) that is independent of the specimen geometry, it is essential to process data in the scaled form $\Delta V_{2} / F$ (see Fig 3c).

\section{EXPERIMENTAL METHODS, DATA AND ANALYSIS}

\section{Materials and methods}

Long-term imbibition tests have been carried out on two fine-grained oolitic limestones, Ancaster Hard White and Portland Base Bed. Both are quarried building stones, widely used in masonry construction. Although their sorptivities are similar, the porosity of the Portland stone used here is larger than that of the Ancaster stone (see Table 1).

Test blocks were either $50 \mathrm{~mm}$ cubes, or $150 \times 50 \times 50 \mathrm{~mm}$ rectangular prisms. None of the surfaces of the blocks were sealed. All blocks were conditioned by drying to constant weight at $45^{\circ} \mathrm{C}$ in a forced air stream, and then cooled to the test temperature. Tests were run in a purposebuilt environmental cabinet at $25 \pm 0.1^{\circ} \mathrm{C}$, with the blocks in lidded trays and resting on porous pads in contact with distilled water. By using lids, evaporative pumping of water through the blocks was prevented, and the release of air in secondary imbibition occurred solely by molecular diffusion without any advective transport. Weights were measured on balances reading to 0.01 or $0.1 \mathrm{~g}$. Each weighing took no more than $20 \mathrm{~s}$. Free water on the inflow surface was removed by brief contact with a damp paper tissue. Weighings were highly repeatable. Evaporation over the measurement interval was negligible. The porosities and solid densities were found by conventional vacuum saturation methods (Hall and Hamilton 2015; Hall and Hamilton 2016), supported by direct measurement of block dimensions (Table 1). 


\section{Imbibition data and analysis}

Imbibition behaviour in all tests is broadly similar to that shown in Fig 1: rapid primary imbibition is followed by a slow secondary stage in which the specimen eventually reaches saturation. Imbibition takes longer to reach completion in Portland limestone than in Ancaster, although the rates of primary imbibition are similar (Fig 4). The $50 \mathrm{~mm}$ Ancaster blocks used reach saturation in about 60 days, while Portland blocks of the same size take about 230 days. This difference is mainly because the amount of air trapped in primary imbibition, $\lambda f$, is twice that in Ancaster. Although Portland has a greater secondary sorptivity than Ancaster, it still takes longer for all the trapped air to escape.

Fig 4 also shows that there is a range of early-time secondary-imbibition data which are linear in $t^{1 / 2}$. It is these data which are used to determine the secondary sorptivity $S_{2}$. In the cases shown in Fig 4 , the time $t_{2}$ which marks the end of the primary imbibition is rather short (about $2 \mathrm{~h}$ ), so that the difference between $t$ and $t^{\prime}$ is negligible. The linear portion of the data occurs over the interval 1-7 days for Ancaster, but rather later, 3-21 days, for Portland. This is an important observation, and means that it may not be possible to use a fixed data interval for all materials in a standard test.

These observations taken together confirm that $S$ and $S_{2}$ depend on different material properties, and suggests that these quantities may be independent measures of material performance. The underlying relation between the secondary sorptivity $S_{2}$ and material properties expressed in Equation 5 is discussed fully elsewhere (Hall et al. 2017). However, without detailed analysis, it can be seen that $S_{2} \sim \lambda^{1 / 2} f$, since $S_{2}=\lambda f B$, and, from Eqn 5, $B \sim\left(D_{\mathrm{a}}^{\prime} / \lambda f\right)^{1 / 2}$ where $D_{\mathrm{a}}^{\prime}=D_{\mathrm{a}} f / \tau$. The scaling factor $\lambda^{1 / 2} f$ may largely account for the greater value of $S_{2}$ in Portland stone than in Ancaster stone.

Test results also demonstrate the importance of scaling the data by total face area $F$ rather than by inflow face area $A$. Complete imbibition curves for three tests using Ancaster limestone specimens of different shape and orientation are shown in Fig 5. These experimental curves should be compared with the corresponding schematic, Fig 3c. It is only by scaling the imbibition data $\Delta V_{2}$ by the total unsealed face area $F$ rather than by the area of the inflow face $A$ that it is possible 
to evaluate a secondary sorptivity $S_{2}$ which is independent of the specimen shape and size.

\section{TEMPERATURE VARIATION OF THE SECONDARY SORPTIVITY}

For a given material, the primary sorptivity $S$ varies as the quantity $(\sigma / \eta)^{1 / 2}$ where $\sigma$ is the surface tension of water and $\eta$ its viscosity. This quantity increases with increasing temperature, for example by 47 per cent from $5^{\circ} \mathrm{C}$ to $40^{\circ} \mathrm{C}$, and $S$ increases correspondingly (Ioannou et al. 2017).

There is no published information on the temperature dependence of the secondary sorptivity $S_{2}$. However, Eqn 5 suggests that the temperature variation of $S_{2}$ is controlled mainly by that of the quantity $\left(D k_{\mathrm{H}} T\right)^{1 / 2}$. The diffusivity $D$ varies as $T / \eta$ (Ferrell and Himmelblau 1967), so that $S_{2}$ varies as $\left(k_{\mathrm{H}} / \eta\right)^{1 / 2} T$. The Henry constant $k_{\mathrm{H}}$ and the viscosity $\eta$ both fall with rising temperature (Hall and Hoff 2012), but $\eta$ changes more than $k_{\mathrm{H}}$. Calculations indicate that $S_{2}$ should increase by about 30 per cent from $5^{\circ} \mathrm{C}$ to $40^{\circ} \mathrm{C}$. Fig 6 shows complete imbibition curves measured in exploratory tests at 10 and $25^{\circ} \mathrm{C}$ on a $50 \mathrm{~mm}$ cube of Ancaster limestone. There is little overall difference between the curves, but the secondary sorptivity $S_{2}$ is slightly higher at $25^{\circ} \mathrm{C}$ than at $10^{\circ} \mathrm{C}$, as predicted.

\section{CONCLUSIONS}

There is current interest in secondary imbibition (or absorption) for characterizing concrete and other materials, but at present the derived secondary sorptivity has little basis in fundamentals. The authors have attempted here to provide such a theoretical basis, and draw the following conclusions from the work described.

1. Long-term water-imbibition data on building limestones show that primary imbibition is followed by a slow, continuing secondary absorption of water, which eventually brings the material to a state of saturation. The new data confirm an earlier isolated result on brick. It is to be expected that the general behaviour described here is to be found in other porous construction materials, notably in concrete and mortars.

2. Theoretical analysis of a sharp-front model shows that the initial rate of secondary imbibition 
varies as $\left(t^{\prime}\right)^{1 / 2}$, the square root of the elapsed time measured from the end of primary imbibition.

3. Theoretical analysis also shows that the initial rate of secondary imbibition varies as the total unsealed face area $F$ of the test specimen, not as the inflow face area $A$. The secondary sorptivity should therefore be defined in relation to the quantity $\Delta V_{2} / F$, not $\Delta V_{2} / A$.

4. The secondary sorptivity so defined characterizes the tendency of a porous material to release trapped or entrained air by molecular diffusion.

5. Results show that, given sufficient time, porous materials in contact with supply of water reach a state of saturation in which all the open porosity is water-filled. This has implication for all porous materials in long-term contact with moist ground, not only in construction and infrastructure engineering, but also in archaeological sites and in nuclear waste installations.

6. The value of the secondary sorptivity as a material property in characterization and specification remains to be established.

There are several open questions still to be answered. These include:

1. Do test data consistently show that early-time secondary imbibition data scale as $t^{\prime 1 / 2}$, the square root of the elapsed time measured from the end of primary imbibition?

2. Do tests confirm that the secondary sorptivity increases slowly with rising temperature, as predicted by Eqn 5 ?

3. What is the rôle of advection (evaporative pumping) in accelerating the release of trapped air, both in test procedures and in moisture dynamics in buildings and other engineering structures?

4. How effective are surface coatings and seals in preventing the release of trapped air, both from test specimens and from building materials in use?

5. How does the secondary sorptivity relate to other properties of the test material, and to its performance characteristics, particularly to measures of durability?

The work described contributes to the understanding water dynamics in porous construction 
materials, and associated test methods.

\section{Acknowledgments}

AH acknowledges financial support from the UK Engineering and Physical Sciences Research Council (grant number EP/L014041/1). 


\section{APPENDIX I. SECONDARY IMBIBITION IN A CYLINDRICAL SPECIMEN}

Cylindrical specimens are sometimes used in imbibition tests. If all surfaces are unsealed, there are outward air-diffusion paths at right angles to the two flat end faces, and also radial paths outwards, normal to the lateral surface. If the cylinder is of length $L$ and diameter $2 R$, the volume of the saturation zone

$$
V_{\mathrm{sz}}=\pi\left[L R^{2}-\left(L-2 y_{\mathrm{sf}}\right) x_{\mathrm{sf}}^{2}\right]
$$

where $y_{\mathrm{sf}}$ is the normal distance from an end-face to the saturation front, $x_{\mathrm{sf}}=R-r_{\mathrm{sf}}$ is the distance from the lateral (cylinder) face to the saturation front, and $r_{\mathrm{sf}}$ is the radial position of the saturation front measured from the axis of the cylinder $(r=0)$. Just as for a rectangular block, $\Delta V_{2}=\lambda f V_{\mathrm{sz}}$, but now $\max \left(V_{\mathrm{sz}}\right)=\pi L R^{2}=V_{\mathrm{tot}}$ when $y_{\mathrm{sf}}=L / 2$ or when $x_{\mathrm{sf}}=R$, whichever occurs first. This maximum value marks the end of the secondary process. For a homogeneous material, $x_{\mathrm{sf}} \geq y_{\mathrm{sf}}$ at all times during secondary imbibition, although at early times $x_{\mathrm{sf}} \approx y_{\mathrm{sf}}$.

To a good approximation, the saturation fronts at $x_{\mathrm{sf}}$ and at $y_{\mathrm{sf}}$ move independently. The fronts parallel to the end faces advance unidirectionally, and $y_{\mathrm{sf}}=B t^{\prime 1 / 2}$. The fronts reach the $L / 2$ centre-plane at time $t_{\mathrm{cp}}^{\prime}=(L / 2 B)^{2}=\left(\lambda f L / 2 S_{2}\right)^{2}$.

The circular saturation-front that is parallel to the lateral surface moves radially inwards such that it reaches position $x_{\mathrm{sf}}$ at time

$$
t^{\prime}=\frac{R^{2}}{2 B^{2}}\left[1-\left(\frac{R-x_{\mathrm{sf}}}{R}\right)^{2}\left(1+2 \ln \frac{R-x_{\mathrm{sf}}}{R}\right)\right]
$$

This result is derived from the solution to a related radial-flow problem published elsewhere (Hall 2017). Two simple results from this are useful. First, at early times, $x_{\mathrm{sf}} \approx B t^{\prime 1 / 2}=\left(S_{2} / \lambda f\right) t^{1 / 2}$. Second, the front reaches the cylinder axis $\left(x_{\mathrm{sf}}=R, r_{\mathrm{sf}}=0\right)$ at $t_{\mathrm{ca}}^{\prime}=\frac{1}{2}(R / B)^{2}=\frac{1}{2}\left(\lambda f R / S_{2}\right)^{2}$.

The total secondary imbibed volume $\Delta V_{2}=\lambda f V_{\mathrm{sz}}$ is obtained by combining the air-diffusion process to the end faces with that to the lateral surface by means of Eqn A1. Thus in a cylinder 
with all faces unsealed, so that $F=2 \pi R(R+L)$, the cumulative secondary imbibition is

$$
i_{2}=\Delta V_{2} / F=\frac{\lambda f}{2 R(R+L)}\left[L R^{2}-\left(L-2 y_{\mathrm{sf}}\right)\left(x_{\mathrm{sf}}\right)^{2}\right]
$$

where a given $x_{\mathrm{sf}} \leq R$ is reached at time $t^{\prime}$ calculated from Eqn $\mathrm{A} 1$, at which time the corresponding $y_{\mathrm{sf}}=B t^{\prime 1 / 2}$. The cylinder is saturated at time $t^{\prime}=(L / 2 B)^{2}$ or $t^{\prime}=\frac{1}{2}(R / B)^{2}$, whichever is the smaller. The converging radial flow ensures that if $L / R>2^{1 / 2}$ the saturation front reaches the cylinder axis before the axial flow reaches the centre-plane. 


\section{APPENDIX II. NOTATION}

The following symbols are used in this paper:

$A=$ area of inflow face;

$B=\left(2 B^{\prime}\right)^{1 / 2}$ factor in Eqn 5;

$B^{\prime}=$ factor in Eqn 5;

$D_{\mathrm{a}}=$ diffusivity of air in water;

$E=$ total edge length;

$f=$ volume-fraction porosity;

$F=$ total face area;

$j=$ flux of dissolved air;

$i=$ cumulative imbibed volume;

$k_{\mathrm{H}}=$ Henry's law constant;

$L=$ length of a cylindrical test specimen;

$p_{\mathrm{a}}=$ pressure of trapped air;

$p_{0}=$ air pressure at surface of specimen;

$r_{\mathrm{sf}}=$ radial coordinate of saturation front;

$R=$ radius of a cylindrical test specimen;

$\mathbf{R}=\operatorname{gas}$ constant $\left(4.184 \mathrm{~J} \mathrm{~mol}^{-1} \mathrm{~K}^{-1}\right)$;

$S=$ (primary) sorptivity;

$S_{\mathrm{s}}=$ secondary sorptivity as defined in Eqn 1;

$S_{2}=$ secondary sorptivity as defined in Eqn 8;

$t=$ elapsed time from start of imbibition;

$t_{1}=$ time at which primary imbibition is complete;

$t_{\mathrm{sat}}=$ time at which secondary imbibition is complete;

$t^{\prime}=$ elapsed time from $t=t_{1} ;$

$T=$ absolute (kelvin) temperature; 


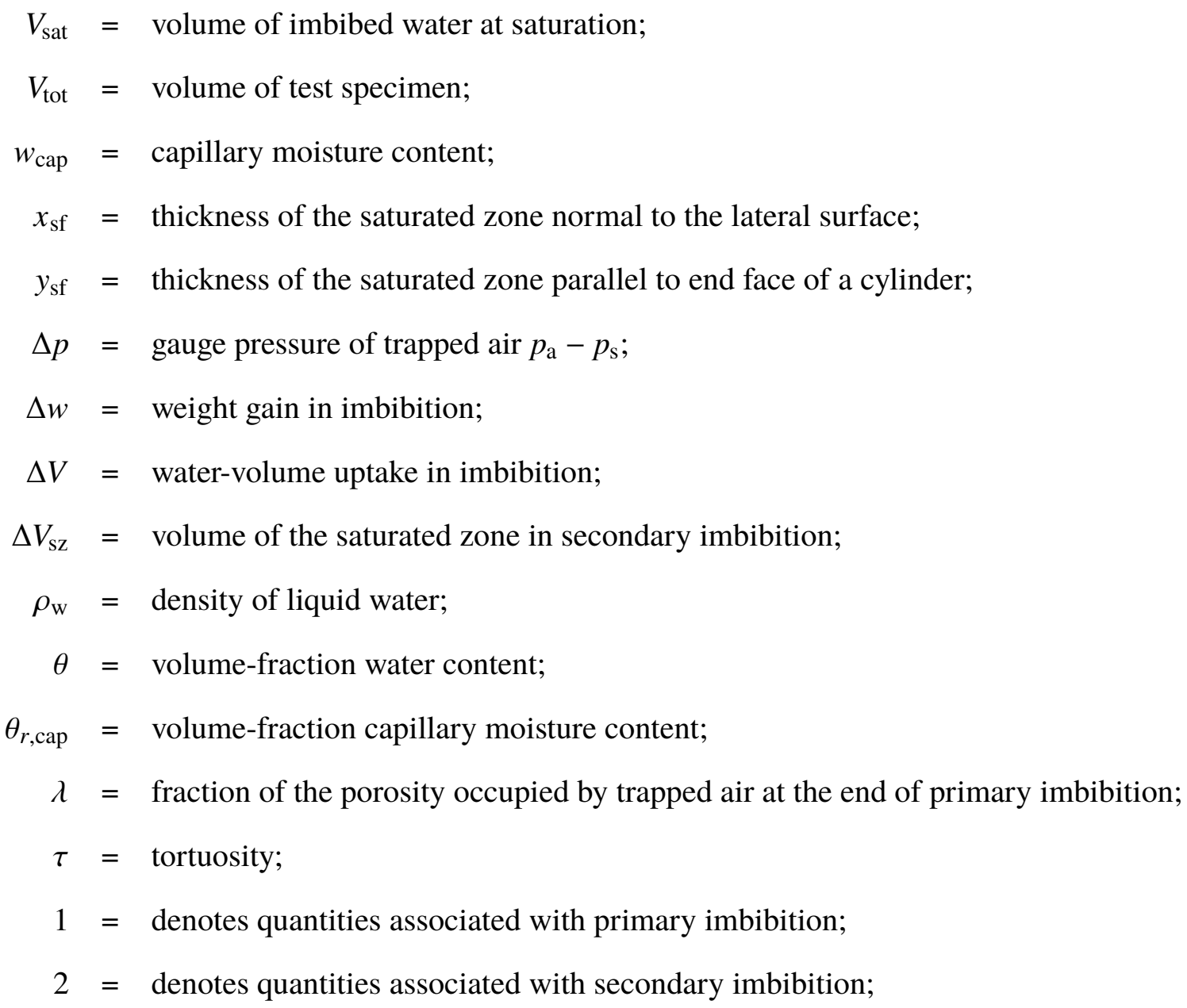




\section{REFERENCES}

Alava, M., Dubé, M., and Rost, M. (2004). “Imbibition in porous media.” Adv. Phys., 53, 83-175. ASTM (2004). "Standard test method for measurement of rate of absorption of water by hydrauliccement concretes." C1585-04, ASTM International, West Conshohocken, Pa.

Blunt, M. (2017). Multiphase Flow in Permeable Media. Cambridge University Press, Cambridge. Fagerlund, G. (1993). "The long time water absorption in the air-pore structure of concrete.” Report TVBM-3051, Division of Building Materials, Lund Institute of Technology, Lund University, Lund, Sweden.

Ferrell, R. T. and Himmelblau, D. M. (1967). "Diffusion coefficients of oxygen and nitrogen in water." J. Chem. Eng. Data, 12, 111-115.

Ghasemzadeh, F. and Pour-Ghaz, M. (2015). "Effect of damage on moisture transport in concrete." J. Mater. Civ. Eng., 27, 04014242.

Gummerson, R. J., Hall, C., and Hoff, W. D. (1980). "Capillary water transport in masonry structures: building construction applications of Darcy's law." Construction Papers, 1, 17-27.

Hall, C. (1989). "The sorptivity of mortars and concretes: a review." Mag. Concr. Res., 41, 51-61.

Hall, C. (2017). "Capillary water absorption by a porous cylinder.” J. Building Physics, in press.

Hall, C. and Hamilton, A. (2015). "Porosity-density relations in stone and brick materials." Mat. Struct., 48, 1265-1271.

Hall, C. and Hamilton, A. (2016). "Porosities of building limestones: using the solid density to assess data quality.” Mat. Struct., 49, 3969-3979.

Hall, C., Hamilton, A., and Beaudoin, N. (2017). "Long-term capillary imbibition and the diffusion of trapped air." Langmuir, in preparation.

Hall, C. and Hoff, W. D. (2002). Water Transport in Brick, Stone and Concrete. Taylor and Francis, New York, first edition.

Hall, C. and Hoff, W. D. (2012). Water Transport in Brick, Stone and Concrete. Taylor and Francis, New York, second edition.

Henkensiefken, R., Castro, J., Bentz, D., Nantung, T., and Weiss, J. (2009). "Water absorption 
in internally cured mortar made with water-filled lightweight aggregate." Cem. Concr. Res., 39, 883-892.

Hens, H. (1976). "Die hygrischen Eigenschaften von Ziegel." Proc. 4th Int. Brick Masonry Conf., Bruges, pp 2.a.10-1-13. 26-28 April 1976.

Hirschwald, J. (1912). Handbuch der bautechnischen Gesteinsprüfung. Bornträger, Berlin.

Ioannou, I., Charalambous, C., and C, H. (2017). "The variation of the water sorptivity with temperature." Mat. Struct., submitted.

Kurtis, K., Burris, L., and Alaptai, P. (2016). "Consider functional equivalence: A (faster) path to up-scaling sustainable infrastructure materials compositions." First Int. Conf. on Grand Challenges in Construction Materials, Los Angeles, CA, 380-388. 17-18 March 2016.

Li, W., Pour-Ghaz, M., Castro, J., and Weiss, J. (2012). "Water absorption and critical degree of saturation relating to freeze-thaw damage in concrete pavement joints.” J. Mater. Civ. Eng, 24, 299-307.

Liu, Z. and Hansen, W. (2016). "A geometrical model for void saturation in air-entrained concrete under continuous water exposure." Constr. Build. Mat., 124, 475-484.

Roels, S., Carmeliet, J., Hens, H., Adan, O., Brocken, H., Cerny, R., Pavlik, Z., Hall, C., Kumaran, K., Pel, L., and Plagge, R. (2004). "Interlaboratory comparison of hygric properties of porous building materials." J. Thermal Env. Bldg Sci., 27, 307-325.

Schaffer, R. J. (1932). The Weathering of Natural Building Stones. HMSO, London.

Wei, Z., Falzone, G., Wang, B., Thiele, A., Puerta-Falla, G., Pilon, L., Neithalath, N., and Sant, G. (2017). "The durability of cementitious composites containing microencapsulated phase change materials." Cem. Concr. Composites doi: 10.1016/j.cemconcomp.2017.04.010. 


\section{List of Tables}


TABLE 1. Secondary imbibition: properties of limestone materials

\begin{tabular}{|c|c|c|c|c|c|}
\hline Material & Specimen & $\begin{array}{l}\text { Volume-fraction } \\
\text { porosity } \\
f \\
{[-]}\end{array}$ & $\begin{array}{l}\text { Volume-fraction } \\
\text { trapped-air } \\
\lambda \\
{[-]}\end{array}$ & $\begin{array}{l}\text { Sorptivity } \\
S \\
\mathrm{~mm} / \mathrm{min}^{1 / 2}\end{array}$ & $\begin{array}{l}\text { Secondary } \\
\text { sorptivity } \\
S_{2} \\
\mathrm{~mm} / \mathrm{min}^{1 / 2}\end{array}$ \\
\hline \multirow[t]{6}{*}{ Ancaster } & An01 & 0.150 & 0.11 & 0.53 & $5.9 \times 10^{-4}$ \\
\hline & An02 & 0.166 & 0.12 & 0.69 & $8.3 \times 10^{-4}$ \\
\hline & $\mathrm{An} 03$ & 0.142 & 0.09 & 0.47 & $6.0 \times 10^{-4}$ \\
\hline & An05 & 0.142 & 0.11 & 0.52 & $6.0 \times 10^{-4}$ \\
\hline & An10 & 0.153 & 0.09 & 0.63 & $5.1 \times 10^{-4}$ \\
\hline & An11 & 0.149 & 0.10 & 0.41 & $6.1 \times 10^{-4}$ \\
\hline Portland & Po01 & 0.200 & 0.26 & 0.62 & $1.5 \times 10^{-3}$ \\
\hline
\end{tabular}

Notes: $S_{2}$ estimated from imbibition data over interval 1-7 days for Ancaster specimens, and 3-21 days for Portland specimen. 


\section{List of Figures}

1 Long-term water imbibition in Ancaster limestone, $50 \mathrm{~mm}$ cube, at $25^{\circ} \mathrm{C}$. Inflow is through one $50 \times 50 \mathrm{~mm}$ face. The test block (An03), which is initially dry, has volume-fraction porosity $f=0.14$, and capillary moisture content $\theta_{r \text {,cap }}=0.91 . \quad$. 24

2 Schematic of sharp-front water transport in primary and secondary imbibition. The test block shown can represent either a cuboid prism standing on end, or a right cylinder standing on its circular base. (a) In primary imbibition, water is taken up by capillarity through the base from the free-water reservoir. (b) In secondary imbibition, trapped air diffuses outwards through all unsealed surfaces and a saturation zone of thickness $x_{\mathrm{sf}}$ grows inwards parallel to each surface. The water is supplied to the saturation zone by movement from the reservoir. . . . . . . 25

3 Schematic of primary and secondary imbibition for specimens of different shape and orientation. The cases shown are for cube $a \times a \times a$, and for a rectangular prism $3 a \times a \times a$ with water absorption through an end face $(a \times a)$, and through a side face $(3 a \times a)$. Subplots show $(a)$ the raw weight gain $\Delta w,(b)$ the water volume gain $\Delta V$ scaled by the area of the inflow face $A$, and $(c)$ the water volume gain $\Delta V$ scaled by the total face area $F$. It is assumed that the primary and secondary processes are sequential $($ see text) . . . . . . . . . . . . . . 26

4 Complete water-imbibition curves of Ancaster An01 (+) and Portland Po01 (O) test specimens ( $50 \mathrm{~mm}$ cubes) at $25^{\circ} \mathrm{C}$. See Table 1 for further information on test

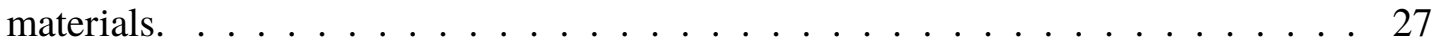


5 Water imbibition in Ancaster limestone specimens of different size and orientation, showing early-time secondary imbibition data scaled by the total face area $F$. All tests at $25^{\circ} \mathrm{C}$, all faces unsealed. $+50 \mathrm{~mm}$ cube, imbibition through one $50 \times 50 \mathrm{~mm}$ face (specimen An05, $f=0.14, S=0.57 \mathrm{~mm} / \mathrm{min}^{1 / 2}, S_{2}=6.0 \times 10^{-4} \mathrm{~mm} / \mathrm{min}^{1 / 2}$ ); O $150 \times 50 \times 50 \mathrm{~mm}$ rectangular prism, imbibition through one $50 \times 50 \mathrm{~mm}$ end face (specimen An10, $f=0.15, S=0.41 \mathrm{~mm} / \mathrm{min}^{1 / 2}, S_{2}=6.1 \times 10^{-4} \mathrm{~mm} / \mathrm{min}^{1 / 2}$ ); $\square 150 \times 50 \times 50 \mathrm{~mm}$ rectangular prism, imbibition through one $150 \times 50 \mathrm{~mm}$ side face (specimen An11, $f=0.15, S=0.63 \mathrm{~mm} / \mathrm{min}^{1 / 2}, S_{2}=5.1 \times 10^{-4} \mathrm{~mm} / \mathrm{min}^{1 / 2}$ ). $\quad 28$

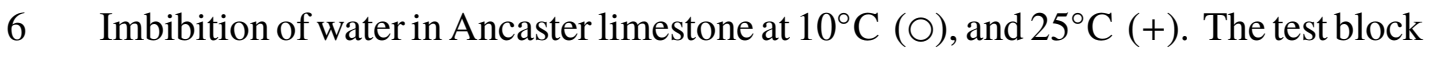
(An02) is a $50 \mathrm{~mm}$ cube with all faces unsealed. $10^{\circ} \mathrm{C}: S=0.57 \mathrm{~mm} / \mathrm{min}^{1 / 2}, S_{2}=$ $7.4 \times 10^{-4} \mathrm{~mm} / \mathrm{min}^{1 / 2} ; 25^{\circ} \mathrm{C}: S=0.69 \mathrm{~mm} / \mathrm{min}^{1 / 2}, S_{2}=8.3 \times 10^{-4} \mathrm{~mm} / \mathrm{min}^{1 / 2}$. $S_{2}$ values are calculated from $\Delta V_{2} / F$ data from 1 day to 1 week. . . . . . . . . . . . 29 


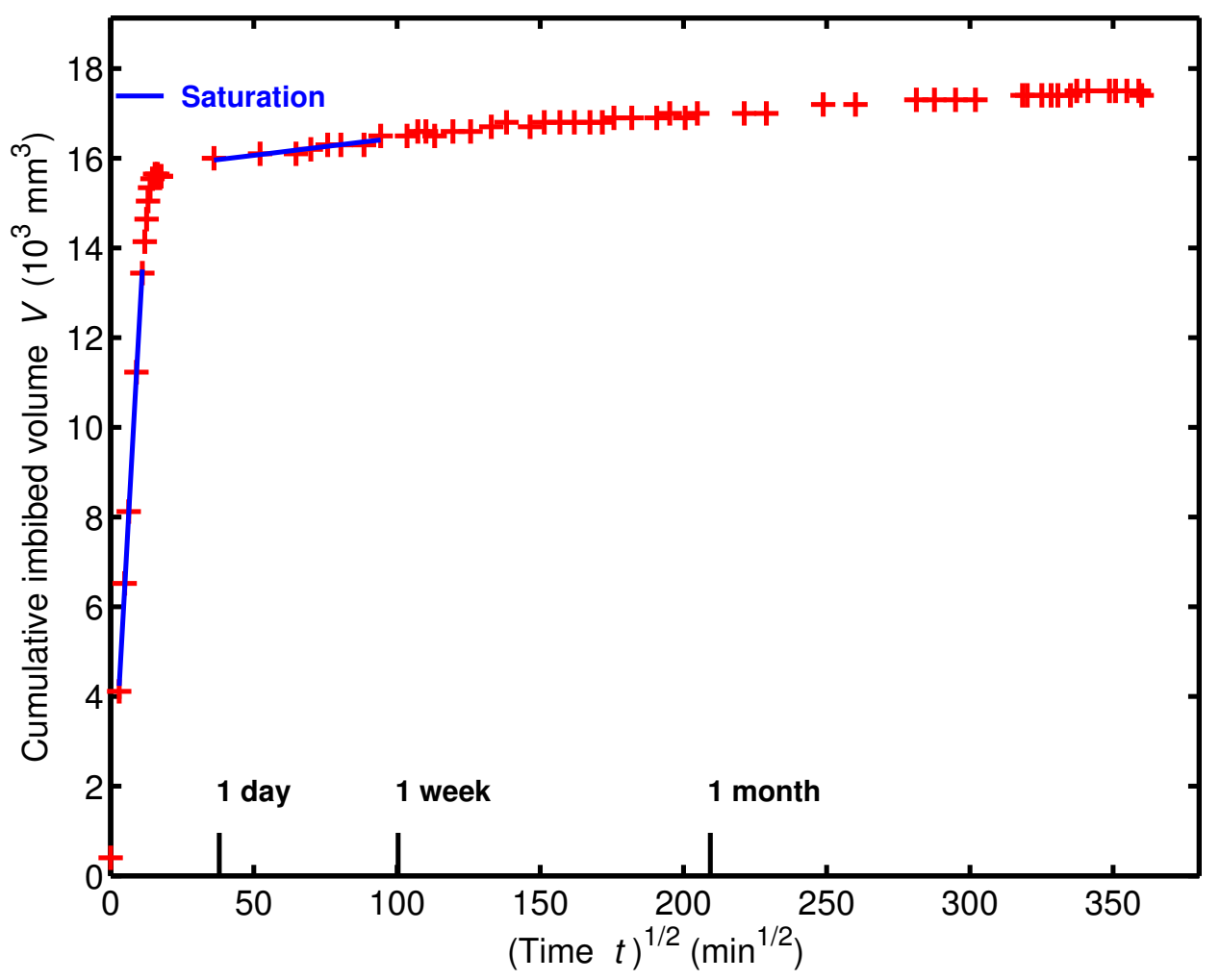

Fig. 1. Long-term water imbibition in Ancaster limestone, $50 \mathrm{~mm}$ cube, at $25^{\circ} \mathrm{C}$. Inflow is through one $50 \times 50 \mathrm{~mm}$ face. The test block (An03), which is initially dry, has volume-fraction porosity $f=0.14$, and capillary moisture content $\theta_{r \text {, cap }}=0.91$. 
a

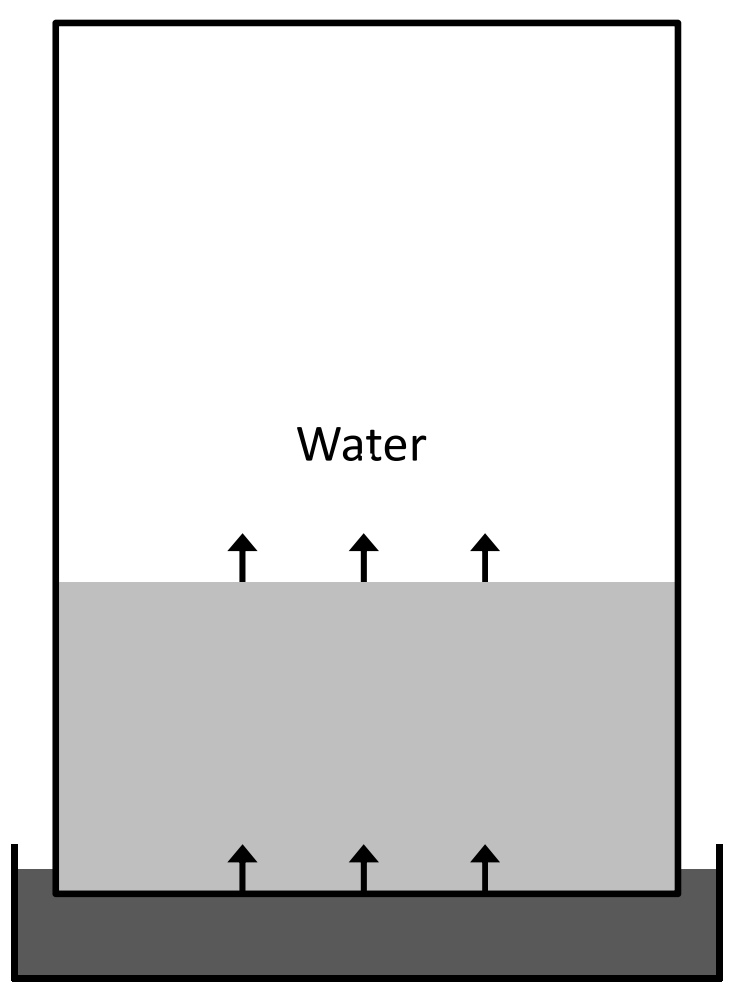

b

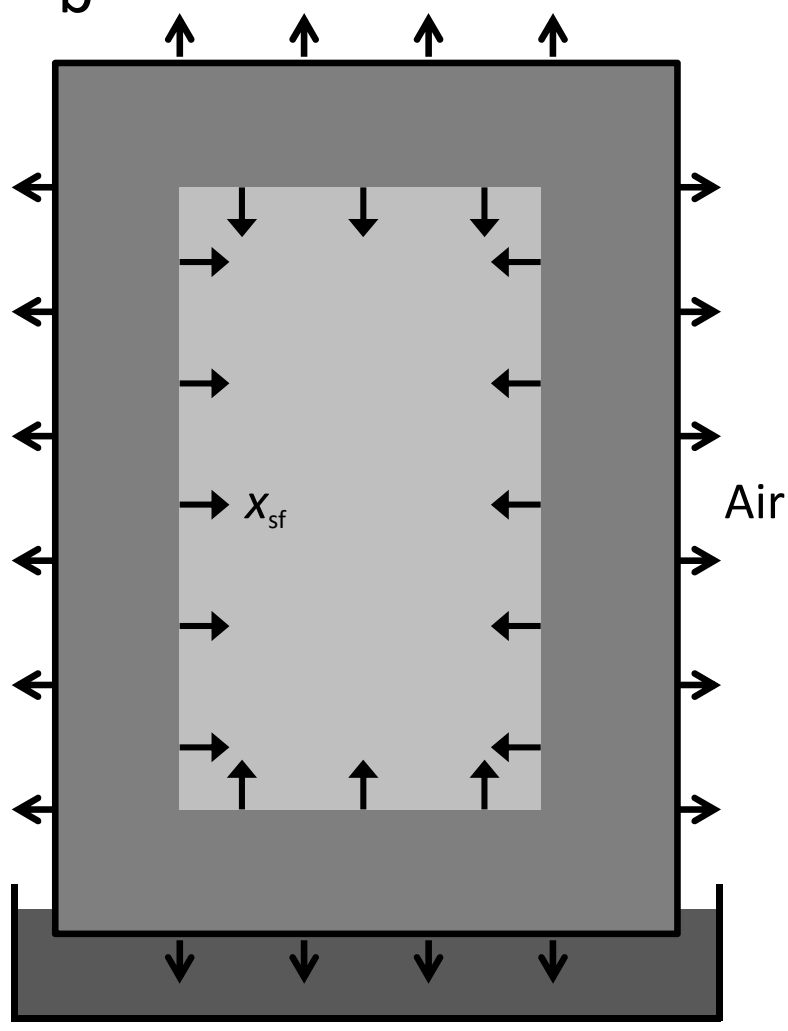

Fig. 2. Schematic of sharp-front water transport in primary and secondary imbibition. The test block shown can represent either a cuboid prism standing on end, or a right cylinder standing on its circular base. (a) In primary imbibition, water is taken up by capillarity through the base from the free-water reservoir. (b) In secondary imbibition, trapped air diffuses outwards through all unsealed surfaces and a saturation zone of thickness $x_{\text {sf }}$ grows inwards parallel to each surface. The water is supplied to the saturation zone by movement from the reservoir. 

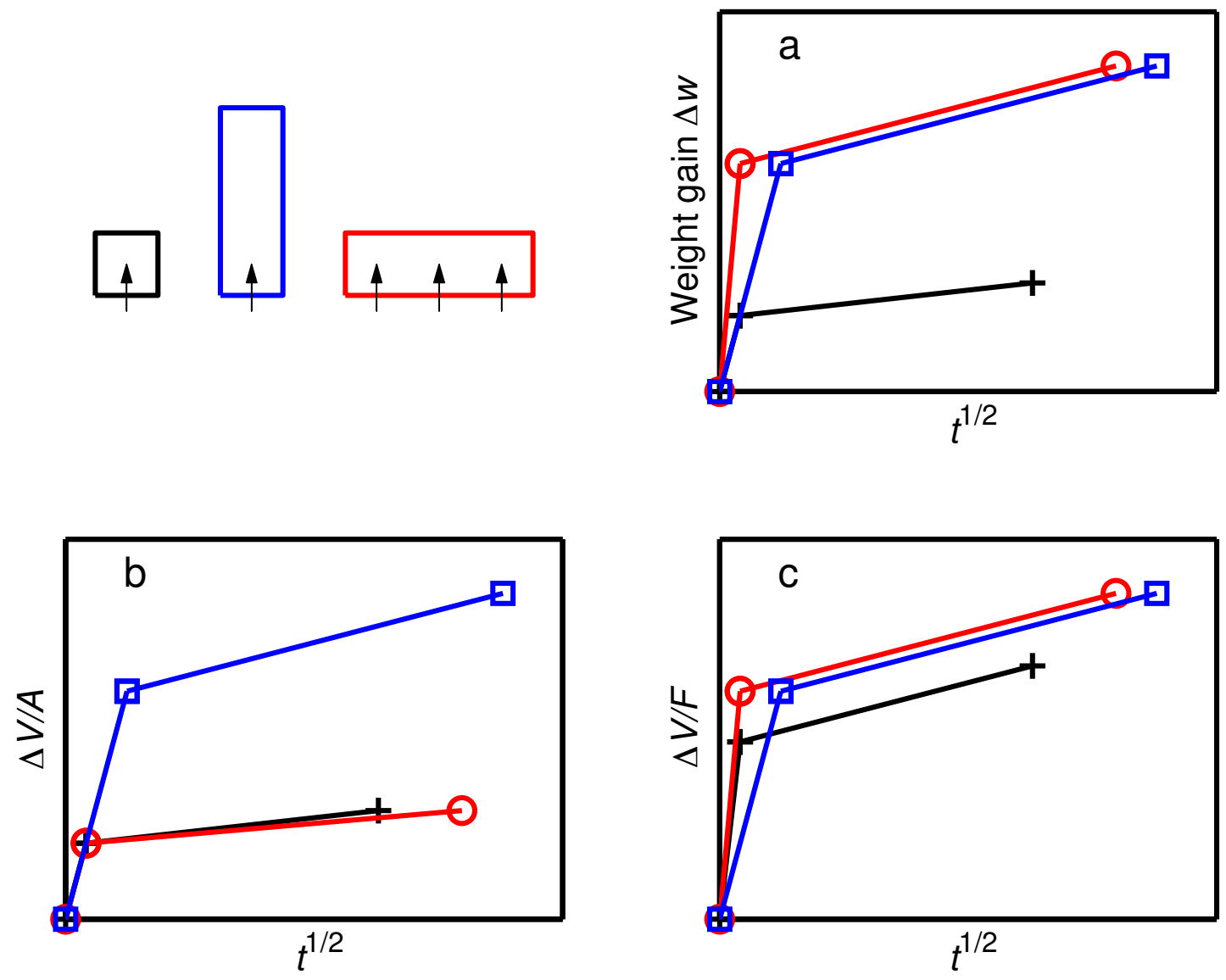

Fig. 3. Schematic of primary and secondary imbibition for specimens of different shape and orientation. The cases shown are for cube $a \times a \times a$, and for a rectangular prism $3 a \times a \times a$ with water absorption through an end face $(a \times a)$, and through a side face $(3 a \times a)$. Subplots show $(a)$ the raw weight gain $\Delta w,(b)$ the water volume gain $\Delta V$ scaled by the area of the inflow face $A$, and (c) the water volume gain $\Delta V$ scaled by the total face area $F$. It is assumed that the primary and secondary processes are sequential (see text). 


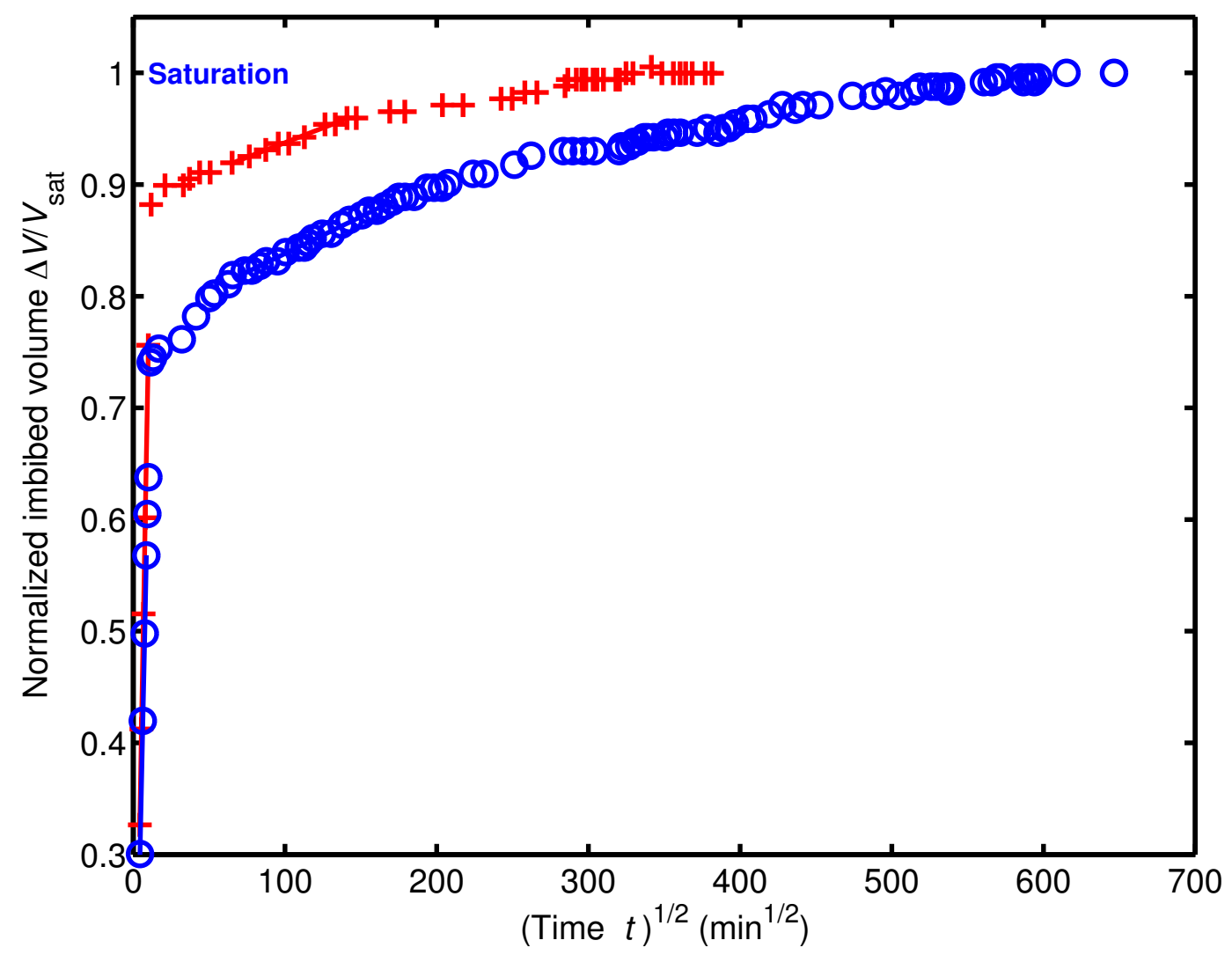

Fig. 4. Complete water-imbibition curves of Ancaster An01 (+) and Portland Po01 (O) test specimens $\left(50 \mathrm{~mm}\right.$ cubes) at $25^{\circ} \mathrm{C}$. See Table 1 for further information on test materials. 


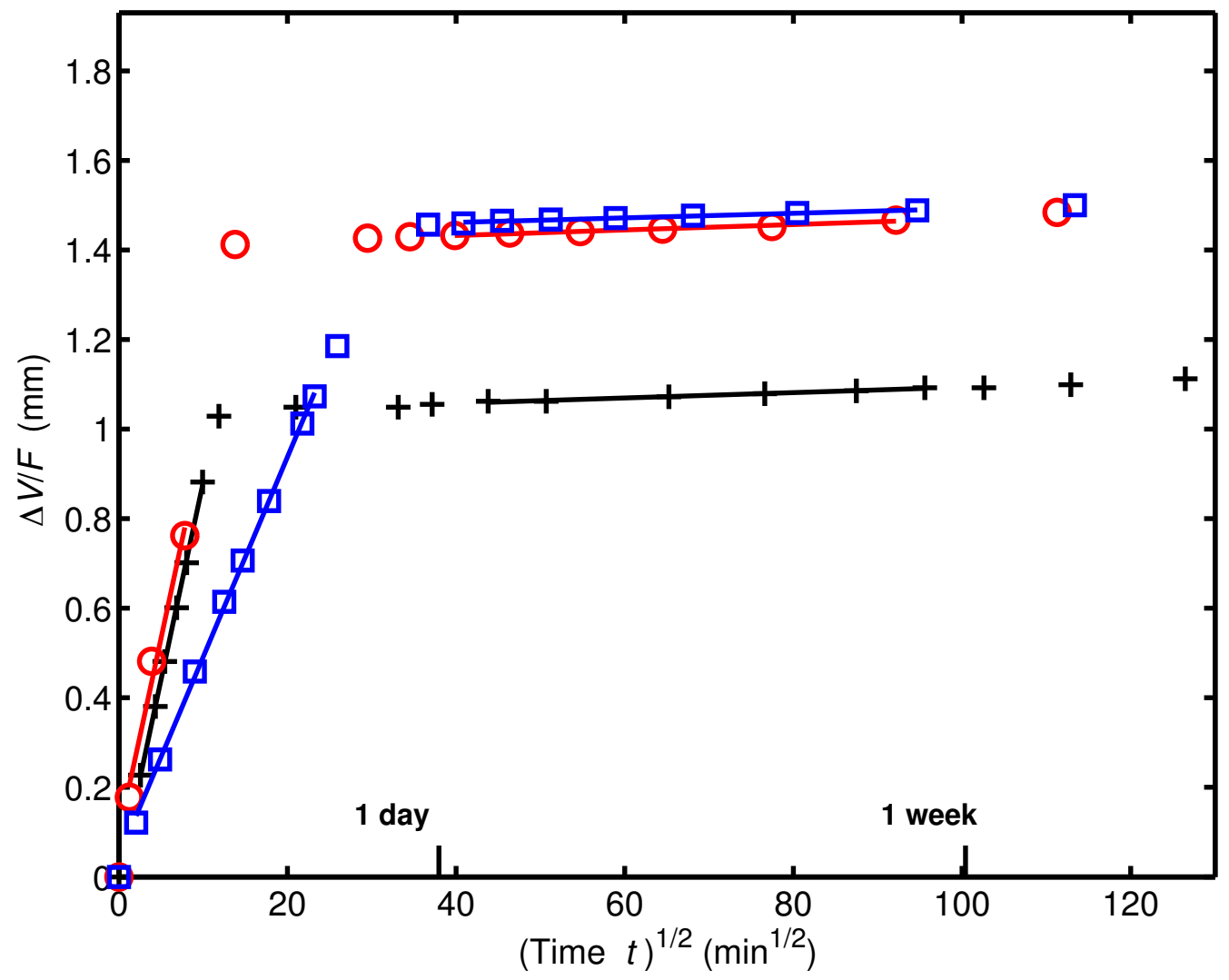

Fig. 5. Water imbibition in Ancaster limestone specimens of different size and orientation, showing early-time secondary imbibition data scaled by the total face area $F$. All tests at $25^{\circ} \mathrm{C}$, all faces unsealed. $+50 \mathrm{~mm}$ cube, imbibition through one $50 \times 50 \mathrm{~mm}$ face (specimen An05, $f=0.14, S=$ $\left.0.57 \mathrm{~mm} / \mathrm{min}^{1 / 2}, S_{2}=6.0 \times 10^{-4} \mathrm{~mm} / \mathrm{min}^{1 / 2}\right) ; \circ 150 \times 50 \times 50 \mathrm{~mm}$ rectangular prism, imbibition through one $50 \times 50 \mathrm{~mm}$ end face (specimen An10, $f=0.15, S=0.41 \mathrm{~mm} / \mathrm{min}^{1 / 2}, S_{2}=6.1 \times$ $\left.10^{-4} \mathrm{~mm} / \mathrm{min}^{1 / 2}\right)$; $\square 150 \times 50 \times 50 \mathrm{~mm}$ rectangular prism, imbibition through one $150 \times 50 \mathrm{~mm}$ side face (specimen An11, $f=0.15, S=0.63 \mathrm{~mm} / \mathrm{min}^{1 / 2}, S_{2}=5.1 \times 10^{-4} \mathrm{~mm} / \mathrm{min}^{1 / 2}$ ). 


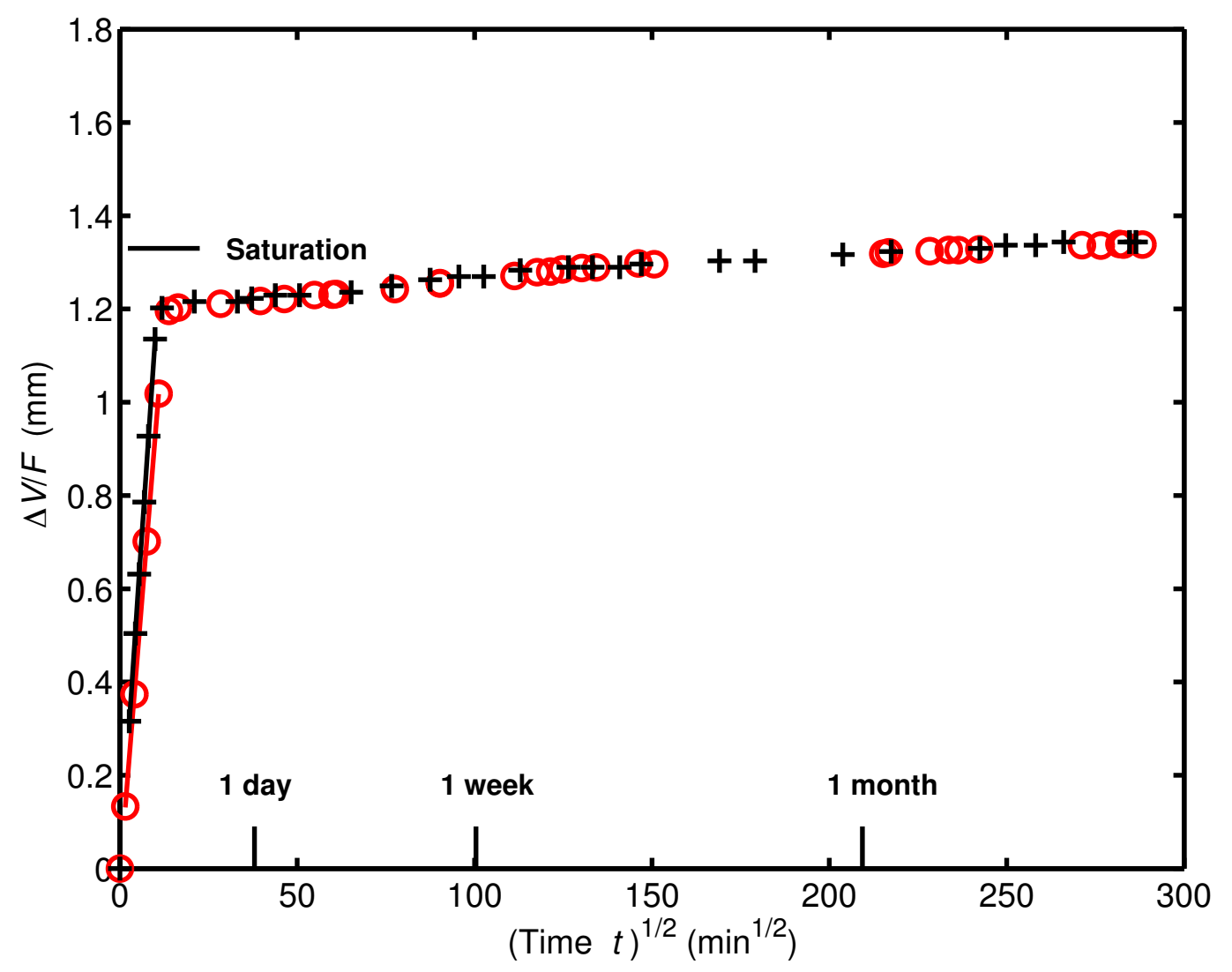

Fig. 6. Imbibition of water in Ancaster limestone at $10^{\circ} \mathrm{C}(\mathrm{O})$, and $25^{\circ} \mathrm{C}(+)$. The test block (An02) is a $50 \mathrm{~mm}$ cube with all faces unsealed. $10^{\circ} \mathrm{C}: S=0.57 \mathrm{~mm} / \mathrm{min}^{1 / 2}, S_{2}=7.4 \times 10^{-4} \mathrm{~mm} / \mathrm{min}^{1 / 2}$; $25^{\circ} \mathrm{C}: S=0.69 \mathrm{~mm} / \mathrm{min}^{1 / 2}, S_{2}=8.3 \times 10^{-4} \mathrm{~mm} / \mathrm{min}^{1 / 2} . S_{2}$ values are calculated from $\Delta V_{2} / F$ data from 1 day to 1 week. 